\title{
Modeling energy consumption and carbon emission in China's household sector
}

\author{
Chenglong Zhang ${ }^{1, a}$, Ding Ma ${ }^{1, b}$, Baoguo Shan ${ }^{1, c}$ \\ ${ }^{1}$ State Grid Energy Research Institute, Beijing, 102209, China \\ aemail: zhangchenglong@sgeri.sgcc.com.cn, bemail:martin8725@126.com, cemail: \\ shanbaoguo@sgeri.sgcc.com.cn
}

\section{Keywords: Household sector; Energy consumption; Carbon emission; China}

\begin{abstract}
With the development of China's economy, we have witnessed the rapid growth of electrical appliance ownership in household sector. Given the great number of population, the energy consumption in household sector is huge in China and consequently causes serious environmental concerns. This paper presents a bottom-up model that focuses on estimation of energy consumption and carbon emission for use of urban and rural household electrical appliance in China between 2010 and 2030. The model employs linear regression analysis to parameterize appliance ownership in terms of household income, urbanization and electrification rates. The findings can be helpful to policy makers as well as household appliance users.
\end{abstract}

\section{Introduction}

Energy consumption is responsible for most of the carbon emissions, but the energy consumption situation is by no means static, nor is it easily predictable.

Residential energy consumption (REC) is the second largest energy use category (10\%) in China although it lags behind the industry by far. Urban residents account for most of the REC (86.9\%). With urban population expected to grow by 20 million per year and residential building area increasing by 2 billion square meters every year through 2020, residential energy consumption (REC) is likely to continue its rapid growth. Other factors may also contribute to a rapid growth of REC, including elevated income levels, changing consumer preferences, as well as penetration of electric appliances and private transportation vehicles. On the other hand, continued energy price reforms, energy efficiency policies and energy conservation awareness may help to restrain further REC growth.

This paper presents a bottom-up methodology for modelling residential appliance uptake as a function of root macroeconomic variables. While such a determination is an interesting result in itself, the results presented will provide the energy community with a foundation for further analysis, especially in the development of bottom-up energy demand forecast and related predictions of carbon emissions. There are two main advantages of such a method. First, an end-use level diffusion model may more accurately capture the structure of energy demand growth by predicting the uptake of energy intensive products instead of assuming a direct relationship between economic activity and energy demand. Second, the ability to mitigate energy related emissions through efficiency depends on the technologies of individual end-uses.

The paper is constructed as follows: Section 2 presents the modelling framework, Section 3 deals with the modelling of physical indicators, Section 4 introduces the modelling results about energy consumption and relevant carbon emissions, and Section 5 tells the discussions about future energy consumption and carbon emissions in China's residential sector.

\section{Modeling framework}

In order to achieve the above mentioned goal, the research work was developed in two steps:

(1) Projecting the main model variables for the different end-uses of the household sector, namely population, urbanization rate, household income, household size, electrification rate 
and other relevant indicators.

(2) Applying a bottom-up methodology to predict electricity demand and related carbon emissions.

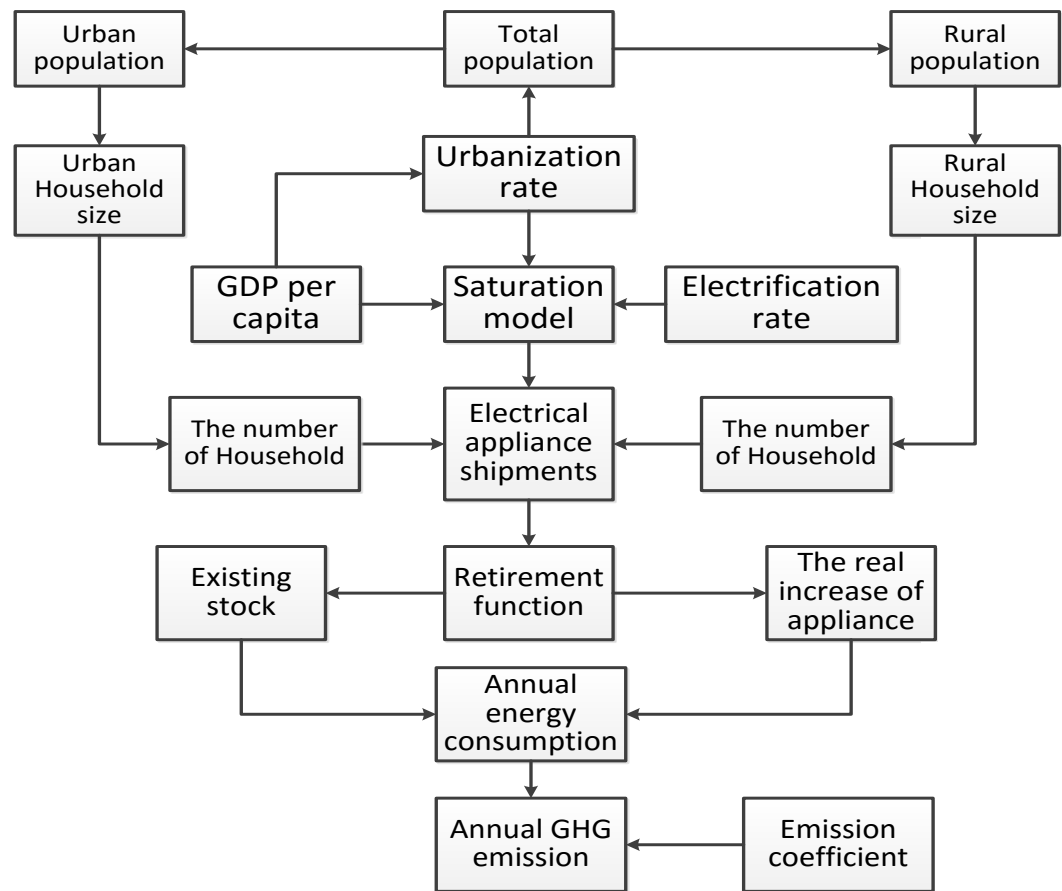

Fig.1. The modeling framework of projecting energy consumption and carbon emission

\section{Main model variables}

\section{Population and Urbanization rate}

Data on urban and rural population for China from 1978 to 2010 are derived from the National bureau of Statistical of China. The total population increased from 0.96 billion in 1978 to 1.34 billion in 2010. The share of urban population increased from $17.9 \%$ to $50.0 \%$ during the same period. Future predictions for total population of China are taken from earlier study. The population of China in 2030 will reach 1.47 million; the annual growth rate will be $3.0 \%$.

As other earlier studies, there is strong empirical evidence that urbanization rate is correlated to GDP per capita. At the same time, it is also clear that non-income effects have played an important role in determining historical urbanization rates, given the wide range of urbanization levels among countries for similar income levels. Hence, we assume a non-structural relationship between urbanization rate and GDP per capita. The relationship used in this study is as follows (Eq.1):

$$
\text { Ulevel }_{\mathrm{t}}=\text { Ulevel }_{\mathrm{MAX}} \times\left\{1-\exp \left(-\alpha \times \text { Income }_{\mathrm{t}}^{\beta}\right)\right\}
$$

$\mathrm{U}_{\text {level }}$ and Income are urbanization rate and GDP per capita; $\alpha$ and $\beta$ are parameters to fit; and $\mathrm{U}_{\text {level max }}$ is the asymptote of China's urbanization. For this paper, the urbanization asymptote has been set at $86 \%$.

The urbanization rate is calculated as follows (Eq.2):

Ulevel $_{\mathrm{t}}=\mathrm{Upop}_{\mathrm{t}} /$ Totpop $_{\mathrm{t}}=\mathrm{Upop}_{\mathrm{t}} /\left(\mathrm{Upop}_{\mathrm{t}}+\right.$ Rpop $\left._{\mathrm{t}}\right)$

$\mathrm{U}_{\text {pop }}$ and $\mathrm{R}_{\text {pop }}$ are urban populations and rural populations. The total population was derived from earlier study, which is detailed in. Via Eq.1, we could obtain urban and rural populations of China till 2030. In 2030, the urban population will be 985 million; the urbanization rate will be $67.1 \%$.

\section{Household income, Household size and Household numbers}

The most obvious determining variable for electrical appliance ownership is average household income, which is approximated by GDP per capita in this paper. GDP data are provided in per 
capita terms, but most electrical appliances are generally purchased at the household level. Therefore we calculated the household income by multiplying GDP per capita by household size. In order to accurately forecast the numbers of households and household income, we use the constant price in 2010. The household sizes in urban and rural areas are estimated by the UN habitat. In 2030, the urban household size is nearly 2.67, while the rural household size is about 3.35.

The household numbers are calculated as follows:

$$
\begin{aligned}
& \mathrm{ZU}_{\mathrm{t}}=\mathrm{Upop}_{\mathrm{t}} / \text { Usize }_{\mathrm{t}} \\
& \mathrm{ZR}_{\mathrm{t}}=\mathrm{Rpop}_{\mathrm{t}} / \text { Rsize }_{\mathrm{t}} \\
& \mathrm{Z}_{\mathrm{t}}=\mathrm{ZU} \mathrm{t}+\mathrm{ZR} \mathrm{t}
\end{aligned}
$$

ZU and ZR denotes urban household numbers and rural household numbers respectively. Z denotes the total household numbers, $\mathrm{U}_{\text {size }}$ and $\mathrm{R}_{\text {size }}$ are urban and rural household size.

\section{Electrification rate and Energy intensity}

China's Electrification rates from 2000 to 2010 are taken from the IEA's world energy outlook 2002 2011. The electrification rates in 2010 was 0.966 (Urban area) and 0.870 (Rural area). The Future trends of electrification rates are taken from other developed countries. We assume that the urban and rural electrification rate will be 0.995 (Urban area) and 0.984 (Rural area) in 2030.

In this study, we concentrate on five major electrical appliances in China's household sector: refrigerators, air conditioners, washing machines, lights, televisions and computers, as shown in Table.1. We approximate the Unit energy consumption based on different sources and estimations.

Table.1 Unit energy consumption and lifetime of major appliances (KWh/year/appliance)

\begin{tabular}{c|ccccc}
\hline Appliance & Refrigerator & $\begin{array}{c}\text { Air } \\
\text { conditioner }\end{array}$ & $\begin{array}{c}\text { Washing } \\
\text { machine }\end{array}$ & Television & Computer \\
\hline Urban area & 600 & 1500 & 144 & 150 & 440 \\
Rural area & 400 & 900 & 144 & 150 & 220 \\
Total lifetime & 12 & 12 & 12 & 12 & 6 \\
\hline
\end{tabular}

\section{Diffusion rate and Retirement rate}

In this study, a diffusion model has been developed. A basic premise of the model is that as the economies develop, households will choose to buy and use electrical appliances. Several factors are considered to have significant impacts on household appliance ownership and they are income, electrification rate and urbanization rate. The diffusion rate is scaled by Diff ${ }_{\max }$, which denotes the saturation level. The diffusion for each appliance in urban/rural area is given by:

$$
\text { Diff }=\frac{\text { Diff }}{\max }
$$

The incremental of electrical appliance $\mathrm{m}$ due to the growth of ownership in year $i$, is calculated as follows:

$$
\Delta S_{i, m}=\operatorname{Diff}_{i, m} \times Z_{i}-\operatorname{Diff}_{i-1, m} \times Z_{i-1}
$$

Due to appliance retirement, the saturation of appliance is calculated as multiplying the initial shipment of the model with a survival factor. The existing stock of model of Model Year $j$ in year $i$ is calculated as:

$$
S_{\mathrm{j}, \mathrm{m}}^{i}=S_{\mathrm{j}, \mathrm{m}} \times\left(1-\sum_{k=1}^{i-j} R R_{k}^{m}\right) ; i>j
$$

$\mathrm{S}$ is the initial shipment of appliance $\mathrm{m}$ in Model Year $j$, and RR is the retirement rate of appliance $m$ at age $(i-j)$. The retirement rate $\mathrm{RR}$ of household appliances is based on the appliance 
age and lifetime according to Eq.9 that shows the case of no retirement (if the appliance age is less than $2 / 3$ of the lifetime), the number of appliances that survive (if the appliance age is more than $2 / 3$ and less than $4 / 3$ of the lifetime) and $100 \%$ retirement (if the appliance age is more than $4 / 3$ of the lifetime):

$$
R R_{i}^{m}=\left\{\begin{array}{l}
0 \% ; \text { if } A_{i}^{m}<\left(\frac{2}{3} L T^{m}\right) \\
1-\left[2-A_{i}^{m} \times\left(\frac{1.5}{L T^{m}}\right)\right] \% ; \text { if }\left(\frac{2}{3} L T^{m}\right)<A_{i}^{m}<\left(\frac{4}{3} L T^{m}\right) \\
100 \% ; \text { if } A_{i}^{m}>\left(\frac{4}{3} L T^{m}\right)
\end{array}\right.
$$

\section{Energy demand and carbon emissions}

The energy consumption for a given end-use may be described as a product of three parameters: the energy intensity of end-use (I), the saturation level of the end-use (S) and the aggregate level or unit used to express energy intensity $(Z)$. The energy intensity $I$ is defined as the average unit energy consumption per appliance, and correspondingly $\mathrm{Z}$ would be the total numbers of households, respectively.

The total energy consumption E and carbon emission can be shown in Eq.10 and Eq.11:

$$
\begin{aligned}
& E=E_{U}+E_{R}=\sum_{m=1}^{5} E_{m U}+\sum_{m=1}^{5} E_{m R}=Z U \times \sum_{m=1}^{5} I_{m, U} S_{m, U}+Z R \times \sum_{m=1}^{5} I_{m, R} S_{m, R} \\
& E m_{C O 2}=E \times E m C_{C O 2}
\end{aligned}
$$

Em denotes the carbon emissions from energy consumption in household sector, EmC is the emission coefficient.

\section{Energy consumption}

Based on the methodology described above, we can obtain the energy consumption of main appliances in urban and rural of China, as shown in Fig.2 and Fig.3. The energy consumption in urban area will increase a lot in the period of 2010-2030, from 681,277 GWh in 2010 to 2,147,763 GWh in 2030. While in the rural area, the energy consumption will increase from 2010, but the growth rate tends to be gentle after 2025. Air conditioners are the highest energy consumption appliances in China as they account, on average for $55 \%$ of the main electrical appliances; televisions accounts for $15 \%$ of the consumption; then refrigerators, with 15\%; televisions, with $9 \%$; computers with $6 \%$ of the energy consumption.

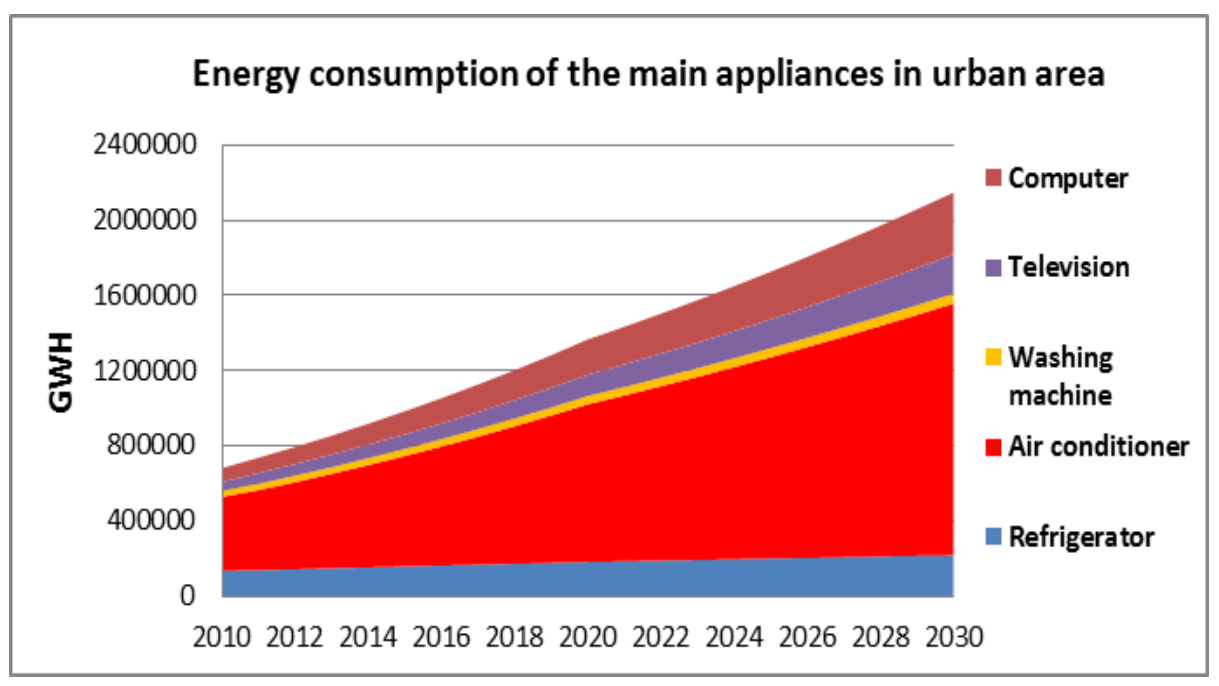

Fig.2 Energy consumption of the main appliances in Urban area (2010-2030) 


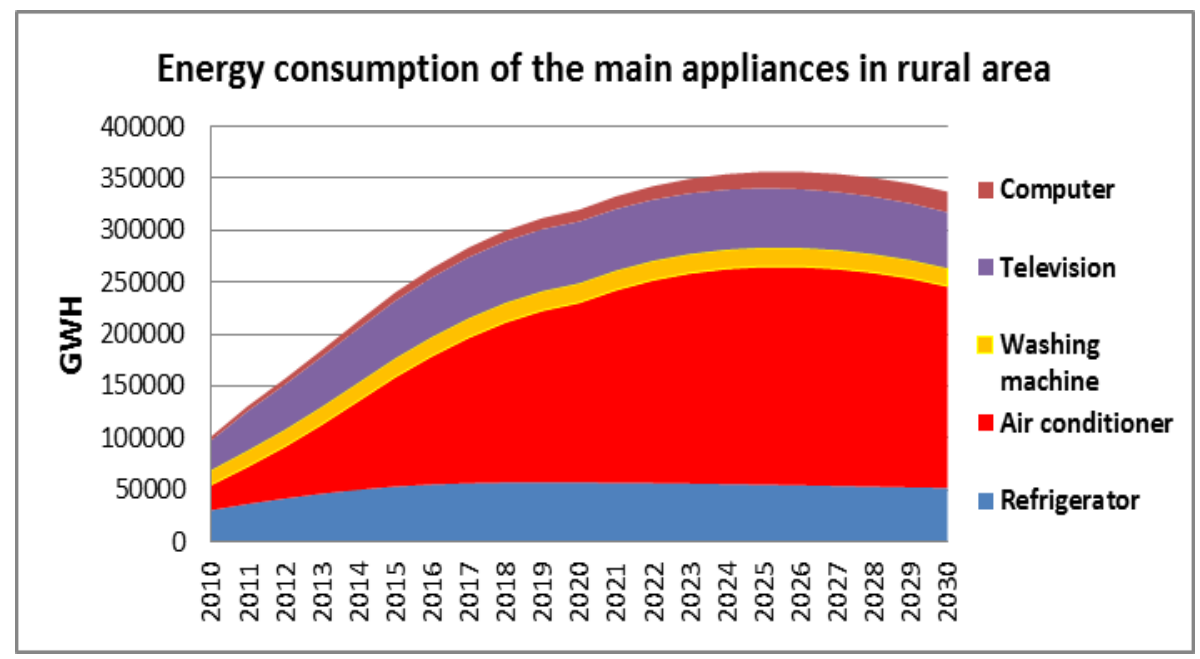

Fig.3 Energy consumption of the main appliances in Rural area (2010-2030)

\section{Carbon emissions}

The carbon emissions from the main electrical appliances between 2010 and 2030. Fig.4 shows the total carbon emissions from electricity consumption in the household sector from 2010 to 2030. Air conditioners are the biggest emitters in China's household sector, followed by refrigerators, computers, televisions and washing machines.

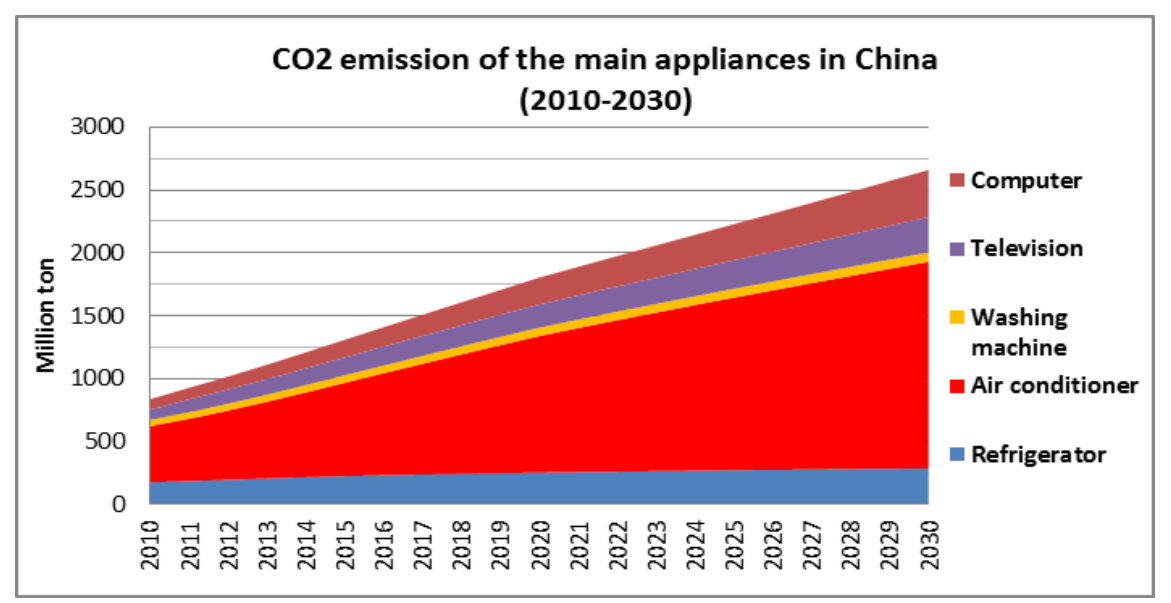

Fig.4 The carbon emission in China's household sector in 2010-2030

\section{Conclusions}

Through this study, we have a better understanding of the diffusion level of China's main electrical appliances in both urban and rural area. The study has found that the diffusion level of televisions, computers and air conditioners still have big growth potential, while the potential of washing machines and refrigerators are limited.

Urban area has a higher diffusion level than rural, as the higher level of urbanization rate and GDP per capita. In urban households, the presence of televisions accounts for the highest saturation, with 3.8 appliances per home for 2030, while washing machines and refrigerators account for 1 appliance per home in 2030. In rural households, the presence of televisions accounts for the highest saturation as well, with 2.5 appliances per home for 2030, while the presence of computers account for 0.6 appliance per home in 2030, far below the diffusion level of urban area.

Considering the annual incremental of electrical appliances will allow for a better estimate of the total energy consumption; in addition, it will provide insight into how much can be done to help reducing energy consumption and carbon emission, and where policy efforts may be most effective. Best available technologies (BAT) for particular appliances are well known. Also well understand 
are the levels of energy efficiency which can be achieved with moderate effort, and which require a more aggressive policy measures. These parameters from the basis of "Efficiency" scenario which can be combined with the diffusion model to describe alternative energy consumption paths for a particular area, or the entire country.

Finally, our study suggests that air conditioners will become an even more critical end-use in the coming decades. In both urban and rural area, air conditioning use will rise rapidly, contributing significantly to carbon and straining peak electricity supply capacity.

\section{References}

[1] Bas J. van Ruijven, Detlef P. van Vuuren, Bert J.M. de Vries. Model projections for household energy use in India. Energy Policy 2011; 39:7747-7761.

[2] Erika Mata, Angela Sasic Kalagasidis, Filip Johnsson. Energy usage and technical potential for energy saving measures in the Swedish residential building stock. Energy Policy 2013; 55:404-414.

[3] Howell MI, Alfstad T, Victor DG, Goldstein G, Remme U. A model of household energy services in a low income rural African village. Energy Policy 2005; 33:1833-1851.

[4] International Energy Agency. World Energy Outlook. OECD.

[5] Isabella Ruble, Sami Karaki. Introducing mandatory standards of select household appliances in Lebanon: A cost-benefit analysis. Energy Policy 2013; 52:608-617.

[6] J Eom, GP Kyle, LE Clarke, PL Patel, SH Kim. China’s building energy use: A long-term perspective based on a detailed assessment. Pacific Northwest National Laboratory 2012.

[7] Jing-Li Fan, Hua Liao, Qiao-Mei Liang, Hirokazu Tatano, Chun-Feng Liu, Yi-Ming Wei. Residential carbon emission evolutions in urban-rural divided China: An end-use and behavior analysis. Applied Energy 2013; 101:323-332.

[8] Jing tao, Suiran Yu. Implementation of energy efficiency standards of household refrigerator/freezer in China: Potential environmental and economic impacts. Applied Energy 2011; 88:1890-1905. 